Article

\title{
Developing and Evaluating a Virtual Reality-Based Navigation System for Pre-Sale Housing Sales
}

\author{
Yi-Kai Juan, Hsing-Hung Chen * and Hao-Yun Chi \\ Department of Architecture, National Taiwan University of Science and Technology, No.43, Sec.4, Keelung Rd., \\ Taipei 106, Taiwan; rik@mail.ntust.edu.tw (Y.-K.J.); M10513018@mail.ntust.edu.tw (H.-Y.C.) \\ * Correspondence: jy955141@hotmail.com; Tel.: +886-2-2737-6658
}

Received: 22 May 2018; Accepted: 5 June 2018; Published: 8 June 2018

\begin{abstract}
Virtual reality (VR) technologies have advanced rapidly in the past few years, and many industries have adopted these cutting-edge technologies for diverse applications to improve their industrial competitiveness. VR has also received considerable recognition in the architecture, engineering, and construction industries, because it can potentially reduce project costs, delivery time, and quality risks, by allowing users to experience unbuilt spaces before breaking ground, resolving construction conflicts virtually, and reviewing complex details in immersive environments. In the real estate market, VR can also play an important role in affecting buyers' housing purchasing decisions, especially for housing markets in Asia, where the pre-sale system is extremely common. Applying VR to the pre-sale housing system is promising, because the concept of pre-sale refers to a strategy adopted by developers that sell housing through agreements on residential units that have not been constructed yet, and VR at this stage could be a useful tool for visual communication in a true-to-scale environment. However, does VR really benefit sales in the housing market? Can clients accept using VR, instead of using traditional materials (i.e., paper-based images and physical models), to navigate and experience housing projects? The objective of this study is to develop a VR-based navigation system for a pre-sale housing project in Taiwan. We invited 30 potential clients to test the system and explore the implications of using it for project navigation. The results reveal that VR enhances the understandings of a project (perceived usefulness) and increases clients' intention to purchase, while the operation of VR (perceived ease-of-use) is still the major challenge to affect clients' satisfaction and the developer's acceptance with respect to applying it to future housing sales.
\end{abstract}

Keywords: virtual reality (VR); housing sales; pre-sale system; technology acceptance model (TAM)

\section{Introduction}

With the advance of information technology and the acceleration of computer computing, virtual reality (VR) technologies have been widely used in education, entertainment, medicare, architectural design, engineering construction, aerospace technology, and other sectors [1-3] with high value. It is regarded by many organizations as an important technological medium to reflect a company's core value and promote customers' relationships with the company [4]. It is also considered as a tool to obtain competitive advantage for enterprises.

VR is a pure virtual digital image that fully utilizes display technology. It is a new milestone in the way we interact with the environment, and how we conceive new approaches in the relationship with reality [5]. It uses computer equipment to simulate and control a three-dimensional virtual world around users' eyes, so that they can interact with the virtual world as if in a real environment [6-8]. In spatial simulations, VR can enhance users' "immersion, interaction and imagination" [9], and become a research tool of effective human-environment interaction [10-14]. 
VR has also received considerable recognition in the architecture, engineering, and construction industries [15]. At the stage of architectural design, VR can enhance the comprehensibility of the design, effectively check design conception and program development, and solve the problem of pipeline collisions in real-time [16,17]. During construction, VR can present information about it in advance with visual design intention and design effect. By mastering the construction methods and specific construction materials, it integrates and reviews the project interface, so as to improve construction efficiency [1]. However, research on VR applications to the sales end is sparse from the perspective of the construction lifecycle. Can VR more effectively promote the rate of pre-sale housing sales in Taiwan than the traditional housing sales model? As to the introduction of VR, will general purchasers and housing developers resist its implementation? These questions are the focus of the housing industry in recent years.

The objective of this study is to develop a VR-based navigation system for a pre-sale housing project in Taiwan. In order to verify the practicality of the system, this study takes an actual pre-sale housing case as an example, and invites 30 subjects to experience the VR-based system. We then make a comparison between the VR-based system and the general navigation system for pre-sale housing. Technology acceptance model-based questionnaires are designed for the experiment to understand customers' attitudes, intention, preferences, and differences of usefulness and usability when using the two systems. The results and expectations are expected to be helpful for future developers importing a VR system.

\section{Characteristics of Pre-Sale Housing Sales}

In the 1960s, rapid economic development in a number of Asian countries, including Taiwan, Hong Kong, China, Singapore, South Korea, and Malaysia, led to an explosion in housing demand. To meet this growing demand, a unique and innovative pre-sale housing system was developed, and has been adopted and developed since then $[18,19]$. Pre-sale housing refers to contracted sales of dwelling units before the construction project is built. Under this system, developers are able to obtain funds from homebuyers in advance, thereby resolving funding problems and dispersing development risk. For the homebuyer, pre-sale housing can be purchased at a discounted price, and they gain ownership rights in advance. Moreover, homebuyers are able to participate and supervise the progress of the housing project to ensure their property rights on completion of the project.

Under the current pre-sale system, developers make use of advertising marketing to create beautiful reception centers and employ professional real estate sales agents. Through architectural models, layout plan of 3D product perspectives, and models coupled with sample housing, the developers attempt to enhance consumers' understanding of the product to stimulate purchase intention. However, consumers often overimagine the product, because of inaccurate graphics and models, or there are cognitive differences due to different presentation methods. Therefore, there is a great gap after the completion of the product.

Applying VR to the pre-sale housing system is promising, because the concept of pre-sale refers to a strategy adopted by developers that sell the housing through agreements that have not been constructed yet. VR, at this stage, could be a useful tool for visual communication in a true-to-scale environment. It can bridge the cognitive gap between pre-sale products and actual products. However, it should be noted that VR has not been widely used by developers, and general homebuyers' operation and recognition of VR have not yet been completely discussed.

\section{VR Navigation System Development on a Pre-Sale Project}

\subsection{Brief Introduction to Pre-Sale Background Information}

This study takes an actual pre-sale case as the object of development and application of the VR system. The experimental case is based in Shilin District, Taipei City, with a floor area of roughly 963 
square meters. There are 2 underground floors, and 5 aboveground floors, and a total of 13 units. The layout of the building 3D model is shown in Figure 1.
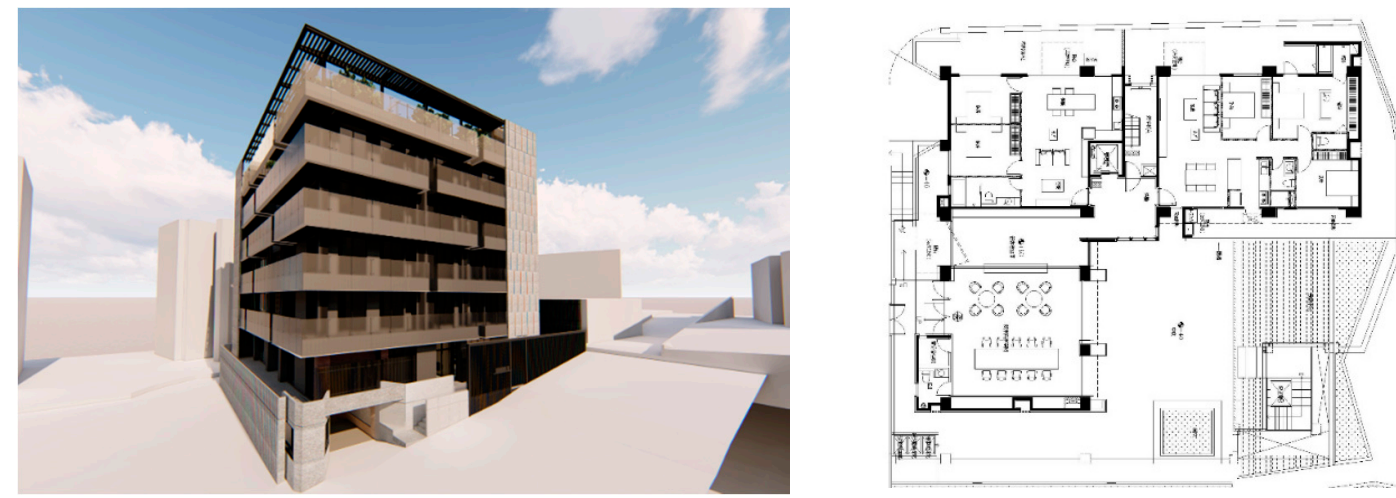

Figure 1. 3D model of the project.

\subsection{System Development}

This study used a wearable wireless headset device (Samsung GearVR) cooperating with a mobile phone (Samsung Glaxy S7) for image processing and output, as well as adopted a handheld controller to develop the VR immersion system and the software of Skethup to produce pictures for constructing the 3D model. Lumion6 and Enscape were used for VR scene rendering. The VR actual browsing section uses 720YUN (Web VR) for node-based walks (Figure 2), and collaborates with Enscape for integrated navigational walks. This study used the walk function of the latter to enable consumers to experience the overall space and reality sense. The space contains the outdoor area of the model, indoor space, and surrounding environment. For the VR's environmental development, one can refer to http:/ /720yun.com/t/x79p5d8g55cr5mn603?pano_id=EQBaL0qy5xqrjNOC.

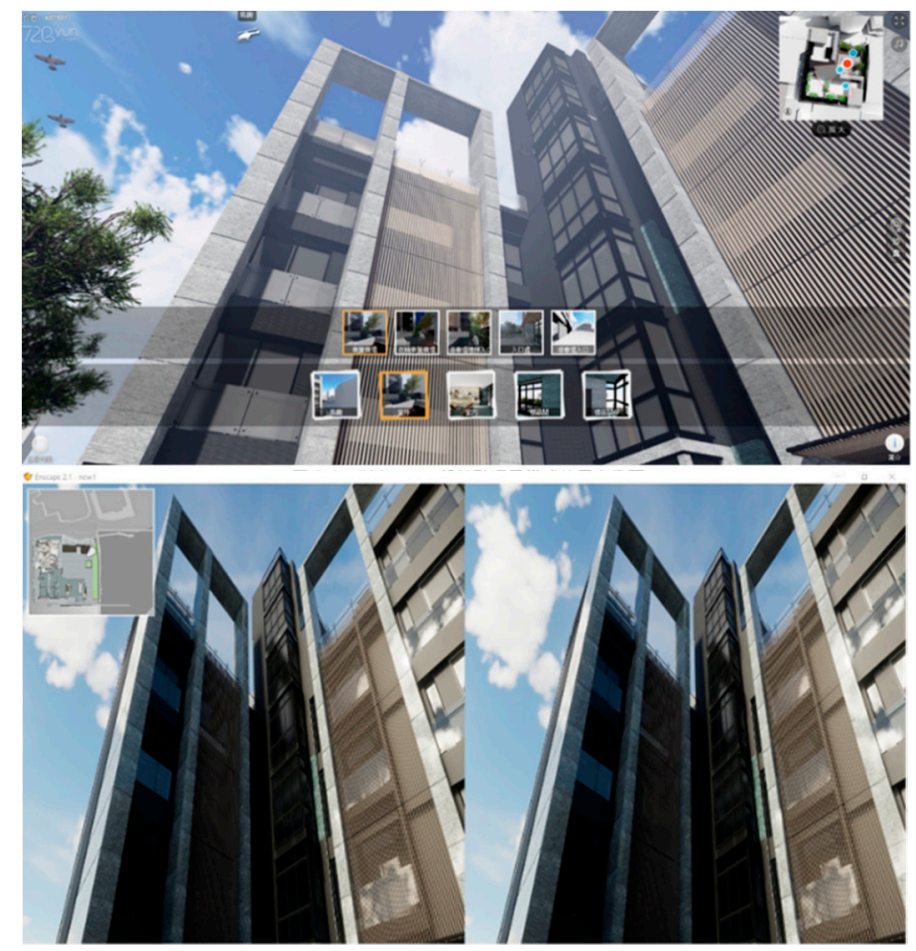

Figure 2. Virtual reality (VR) scene rendering and navigational walks. 


\section{Research Design and System Validation}

\subsection{TAM-Based Questionnair}

Technology acceptance model (TAM) is a behavioral model developed by Davis [20] in 1986 based on the rational theory. Its purpose is to find an effective behavioral model to explain the behaviors and attitudes of users' acceptance of new information systems in computer science. The model provides a theoretical basis for understanding the influences of external factors on users' beliefs, attitudes, and intentions, which further affect their use of technologies. The model is also believed to be widely employed to explain or predict the effects of using information technology.

TAM constructs an acceptance model of users adopting information technology. It believes that cognitive usefulness and usability affect the attitude of using technology and further affect specific behavioral performance. It also argues that people's use of information technology is influenced by their behavioral intentions. In order to verify the practicality of the VR system, this study invites 30 subjects to experience the VR-based system, and then makes a comparison between the VR-based system and the general navigation system for pre-sale housing. TAM-based questionnaires are designed for experiment to understand costumers' attitudes, intention, preferences, and differences of usefulness and usability when using the two systems. A five-point scale (Likert scale) is adopted to determine the respondents' level of agreement, where a score of 5 is "Strongly agree". Under the TAM framework, this study makes adjustments and constructs the following four definitions. The questionnaire is shown in Appendix A.

- Perceived usefulness refers to the degree to which a user believes the use of a system will promote his or her work performance or that it can save efforts. It is the subjective perception that individuals will increase the effectiveness of their work by using a certain information system.

- Perceptive ease of use refers to the degree to which the user perceives that technology is easy to use. If the system is easier to use, the user will be more confident in self-efficacy and self-control, and will have a more positive attitude towards the system.

- Users' attitude toward using information technology is influenced by both perceived usefulness and perceptive ease of use.

- The use of an information system is determined by behavioral intention, while behavioral intention to use is influenced by both individuals' attitudes towards the use of the technology and its perceived usefulness.

\subsection{Research Hypotheses}

Different groups of consumers may have different preferences and acceptance for using a VR system and a general navigation system for pre-sale housing. In particular, VR digital navigation has gradually become a new trend, but it is not popular enough with many consumers. Can VR more effectively promote the rate of pre-sale housing sales in Taiwan than the traditional housing sales model? As to the introduction of VR, will general purchasers and housing developers resist it? To figure out whether there is a difference between applying the VR system and the general navigation system of pre-sale housing for construction guidance, this paper proposes the following four hypotheses, and the framework is shown in Figure 3. 


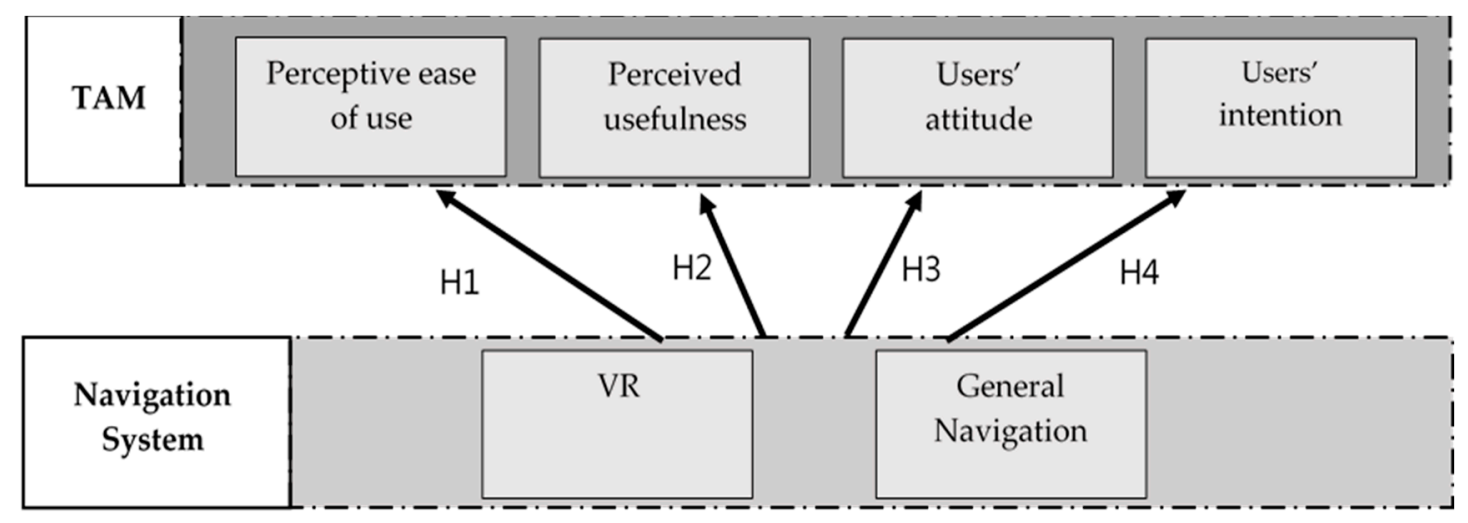

Figure 3. Research hypotheses.

H1: There is a significant difference in perceptive ease of use between the general navigation system and VR navigation system.

H2: There is a significant difference in perceived usefulness between the general navigation system and VR navigation system.

H3: There is a significant difference in users' attitude between the general navigation system and VR navigation system.

H4: There is a significant difference in users' intention to use between the general navigation system and VR navigation system.

\subsection{Experimental Design}

With a random sampling method, this study presents experiments on 30 potential buyers at a pre-sale housing center. The experiment is divided into pre-test (general system) and post-test (VR system). Subjects are first guided by general navigation. In general navigation, the housing sales agent would provide 3D drawings, design specifications, and physical building models (see Figure 4a) for these buyers to understand and experience the housing project. In order to avoid overlapping information and experimental fatigue, as well as decrease the influence of the pre-test, they are invited again to be tested by the VR navigation system after 10 days (an appropriate interval for pre-test and post-test). Both of the tests are conducted for fifteen minutes, and when the experiment is completed, the subjects fill in the TAM-based questionnaires designed by the research team. The experiment is shown in Figure 4.
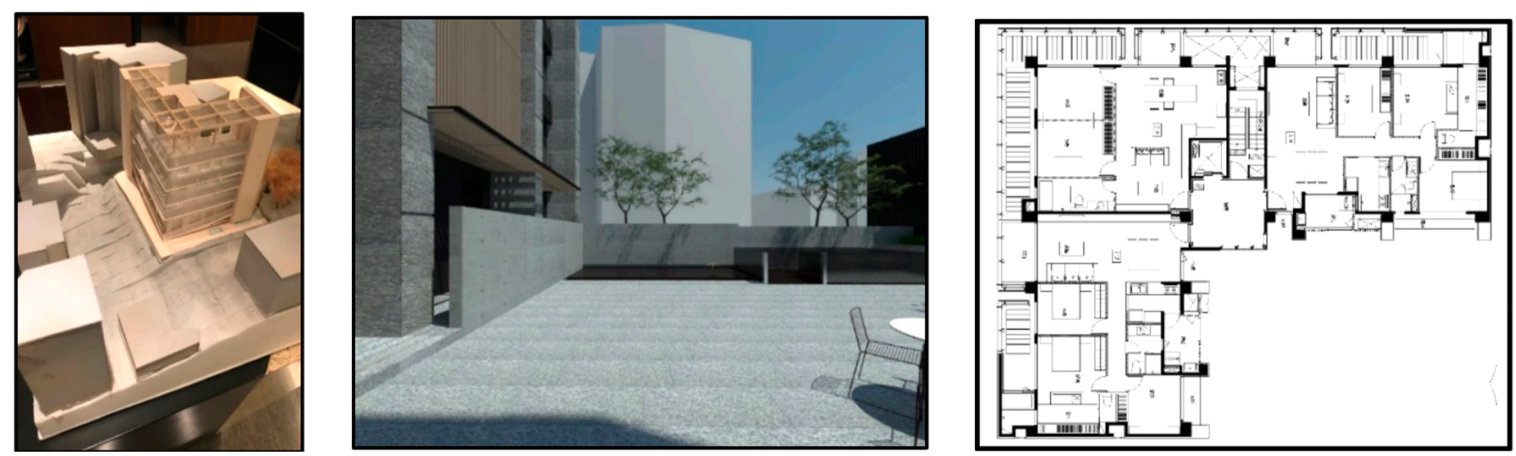

(a)

Figure 4. Cont. 


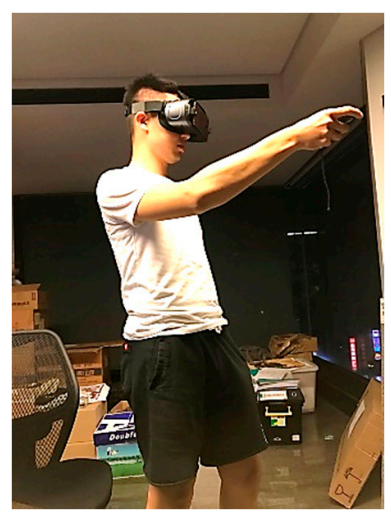

Figure 4. Experimental design. (a) General navigation system; (b) VR navigation system.

\section{Results and Discussion}

\subsection{Results and Analysis}

Of the 30 subjects, 19 are males and 11 females, and all of them are between the ages of 20 to 40 . About $76.7 \%$ of the subjects have used VR technology, but none of them have ever used VR for pre-sale housing navigation.

First, in the reliability part of the questionnaire, Cronbach's $\alpha$ coefficient, most commonly used in sociological research, is taken to measure the consistency of the questions. According to Cuieford [21], if Cronbach $\alpha<0.35$, then there is low reliability; if $0.35 \leqq$ Cronbach $\alpha<0.7$, then reliability is reluctantly acceptable; if Cronbach $\alpha \geqq 0.7$, then reliability is high. This study conducts reliability analysis for each question in the questionnaire. The reliabilities shown in Table 1 all reach a high level, and also show that the questionnaire has a high value of reference. It is noteworthy that the Cronbach $\alpha$ values of the VR system are all slightly smaller than the values of the general navigation system. Since Cronbach $\alpha$ is an internal consistency reliability analysis of items, we assume that the result might be due to respondents who are relatively unfamiliar with the VR operation lacking confidence, which shows in their inconsistency in answering difficult items. This assumption is supported by the Wells and Wollack' study [22], revealing that item discrimination and difficulties might have a large impact on reliability.

Table 1. Reliability analysis (Cronbach $\alpha$ ) of the questionnaire.

\begin{tabular}{ccc}
\hline Dimensions & General Navigation System & VR System \\
\hline Perceptive ease of use & 0.890 & 0.696 \\
Perceived usefulness & 0.923 & 0.897 \\
Users' attitude & 0.910 & 0.867 \\
Users' intention & 0.952 & 0.923 \\
\hline
\end{tabular}

\subsection{Hypothesis Test}

This study focuses on whether there is a difference in the attitudes of consumers when using the general system and VR system during the navigation construction. Since the subjects of the pre-test and post-test are the same, the paired-sample $t$-test is adopted to conduct a hypothesis test. The paired-sample $t$-test, sometimes called the dependent sample $t$-test, is a statistical procedure used to determine whether the mean difference between two sets of observations is zero. In the test, each subject or entity is measured twice, resulting in pairs of observations. This test is used for repeated measure design with the same sample - that is, to measure the same sample before and after the test, to finish the paired-sample test. Thus, we can make a comparison of the mean value of the paired 
data. Table 2 shows the results from perceptive ease of use. Although the mean value of VR is higher than that of general materials, $p$ (the value of significance) $>0.05$, it indicates no significant difference between the pre-test and post-test results. Therefore, it is inferred that $\mathrm{H} 1$ is invalid.

Table 2. Hypothesis test of perceptive ease of use.

\begin{tabular}{|c|c|c|c|c|c|c|}
\hline Item & Mean & Std. Deviation & Mean Deviation & $t$ & $\mathrm{df}$ & $p$-Value \\
\hline General Navigation & 3.625 & \multirow{2}{*}{1.196} & \multirow{2}{*}{-0.317} & \multirow{2}{*}{-1.450} & \multirow{2}{*}{29} & \multirow{2}{*}{0.158} \\
\hline VR & 3.942 & & & & & \\
\hline
\end{tabular}

$t$ is the $t$-statistic ( $t$-test statistic) for a paired sample $t$-test, usually denoting (Mean Deviation)/(Std. Deviation $/ \sqrt{ } \mathrm{n}$ ); $\mathrm{df}$ is the critical value of a $t$-distribution with $(n-1)$ degrees of freedom.

For perceived usefulness, the mean value of VR is higher than that of general materials, $p<0.05$ (Table 3), indicating there is a significant difference between the pre-test and post-test results. Thus, the VR system provides more useful information for construction navigation. Therefore, $\mathrm{H} 2$ is valid.

Table 3. Hypothesis test of perceived usefulness.

\begin{tabular}{|c|c|c|c|c|c|c|}
\hline Item & Mean & Std. Deviation & Mean Deviation & $t$ & $\mathrm{df}$ & $p$-Value \\
\hline General Navigation & 3.107 & \multirow{2}{*}{1.307} & \multirow{2}{*}{-1.273} & \multirow{2}{*}{-5.335} & \multirow{2}{*}{29} & \multirow{2}{*}{0.000} \\
\hline VR & 4.380 & & & & & \\
\hline
\end{tabular}

$t$ is the $t$-statistic ( $t$-test statistic) for a paired sample $t$-test, usually denoting (Mean Deviation)/(Std. Deviation $/ \sqrt{ } \mathrm{n}$ ); $\mathrm{df}$ is the critical value of a $t$-distribution with $(\mathrm{n}-1)$ degrees of freedom.

In order to know whether using VR in construction navigation can effectively improve users' attitude, Table 4 sorts out the pre-test and post-test tests. From the table, the mean value of VR is higher than that of general materials, $p<0.05$, and thus, $\mathrm{H} 3$ is valid. In other words, there is significant improvement in users' attitude after the experiment is conducted with the VR system.

Table 4. Hypothesis test of users' attitude.

\begin{tabular}{|c|c|c|c|c|c|c|}
\hline Item & Mean & Std. Deviation & Mean Deviation & $t$ & df & $p$-Value \\
\hline General Navigation & 3.253 & \multirow{2}{*}{1.259} & \multirow{2}{*}{-1.120} & \multirow{2}{*}{-4.872} & \multirow{2}{*}{29} & \multirow{2}{*}{0.000} \\
\hline VR & 4.373 & & & & & \\
\hline
\end{tabular}

$t$ is the $t$-statistic ( $t$-test statistic) for a paired sample $t$-test, usually denoting (Mean Deviation)/(Std. Deviation $/ \sqrt{ } \mathrm{n}$ ); $\mathrm{df}$ is the critical value of a $t$-distribution with $(n-1)$ degrees of freedom.

Finally, in order to understand whether using VR in construction navigation can effectively enhance users' intention, Table 5 lists the pre-test and post-test results. From the table, the mean value of VR is higher than that of general materials, $p<0.05$, and thus $\mathrm{H} 4$ is valid. There is a significant improvement in users' intention after the experiment is conducted with the VR system.

Table 5. Hypothesis test of users' intention to use.

\begin{tabular}{|c|c|c|c|c|c|c|}
\hline Item & Mean & Std. Deviation & Mean Deviation & $t$ & df & $p$-Value \\
\hline General Navigation & 3.275 & \multirow{2}{*}{1.361} & \multirow{2}{*}{-1.108} & \multirow{2}{*}{-4.461} & \multirow{2}{*}{29} & \multirow{2}{*}{0.000} \\
\hline VR & 4.383 & & & & & \\
\hline
\end{tabular}

Based on all the data, we find that VR significantly contributes to housing sales and consumers' understanding (perceived usefulness) of pre-sale housing. Respondents also hold positive attitude 
towards using VR for space navigation. For the future, there is also a high degree of intention to understand information of pre-sale housing with VR. These findings are all consistent with other studies revealing that VR could be an expressive, interactive, and representative potential of immersive digital technology [5], and its high interactivity, realism, motivation, and usefulness can enhance specific learning and experiencing scenarios [15,23]. Moreover, VR also shows its high potential cooperating with digital technology (e.g., building information modeling techniques), UX (user experience), and interaction design in a wide range of scientific and educational domains [5]. However, VR technology and the ease of use of its operation still need further improvement on the developers' side in this study.

\section{Conclusions}

VR is presently widely used in various industries, and many studies have shown that it can effectively improve their efficiency and improve upon their inefficiencies. Therefore, this study employs VR on a test with consumers of pre-sale housing. In addition to achieving the overall framework of "seeing and gaining", it provides an immersion experience, and studies whether VR can enhance their understanding of pre-sale housing and further stimulate their purchase intention, with the hope to establish an innovative marketing model in the future for the pre-sale market.

Through four aspects of TAM, ease of use, usefulness, attitude, and intention, the study explores consumers' appraisal of VR for the pre-sale market by introducing VR technology. According to the statistics and results of the questionnaire, after experiencing VR, the consumers do think highly of its subsequent development in the pre-sale market. By immersing themselves in the real environment, VR can improve the efficiency of presentations, and get closer to users so as to directly gain product information through interactions with users. It also helps to reduce the perceptive difference in space, and brings new feelings to consumers.

There is still room for improvement in VR's ease of operation and comfort of equipment due to limitations of technology. These are also challenges that developers have to face during its introduction into the pre-sale market. As a whole, consumers still think highly of using VR in the pre-sale market, and expect to make more use of it to make decisions on a housing purchase.

The study further finds that if a dynamic simulation of customer information and real-time presentation of customers' preferences for spatial planning, materials, and facilities can be considered in future projects, then VR technology will positively promote customers' satisfaction with the overall housing purchase. VR can also be combined with building information modeling techniques in a virtual and dynamic manner to enhance the integrity of project planning and to enhance the detailed review of the construction interface to better influence consumers' satisfaction.

Author Contributions: Y.-K.J. led the research activities, conceived and designed the experiments, as well as performed the data analysis. H.-H.C. conducted the experiments and case study, as well as performed the data analysis. H.-I.C. conducted the survey and developed the VR system.

Acknowledgments: This study was financially supported by the Taiwan Building Technology Center from The Featured Areas Research Center Program within the framework of the Ministry of Education (MOE) in Taiwan.

Conflicts of Interest: The authors declare no conflict of interest. 


\section{Appendix A}

Perceived Ease of Use

\begin{tabular}{|c|c|c|c|c|c|c|c|}
\hline \multirow[t]{6}{*}{1.} & \multicolumn{7}{|c|}{ I think it is easy to use the materials provided by general construction navigation. } \\
\hline & & 1 & 2 & 3 & 4 & 5 & \\
\hline & Strongly disagree & $\circ$ & $\circ$ & $\circ$ & $\circ$ & $\circ$ & Strongly agree \\
\hline & \multicolumn{7}{|c|}{ I think it is easy to use VR. } \\
\hline & & 1 & 2 & 3 & 4 & 5 & \\
\hline & Strongly disagree & $\circ$ & $\circ$ & $\circ$ & $\circ$ & $\circ$ & Strongly agree \\
\hline 2. & \multicolumn{7}{|c|}{ The steps of general construction navigation are simple and clear. } \\
\hline & & 1 & 2 & 3 & 4 & 5 & \\
\hline & Strongly disagree & o & $\circ$ & $\circ$ & $\circ$ & $\circ$ & Strongly agree \\
\hline & \multicolumn{7}{|c|}{ The steps to operate VR are clear and understandable. } \\
\hline & & 1 & 2 & 3 & 4 & 5 & \\
\hline & Strongly disagree & $\circ$ & $\circ$ & $\circ$ & $\circ$ & $\circ$ & Strongly agree \\
\hline \multirow[t]{6}{*}{3.} & \multicolumn{7}{|c|}{ I think it is easy to understand the materials of general construction navigation. } \\
\hline & & 1 & 2 & 3 & 4 & 5 & \\
\hline & Strongly disagree & 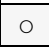 & $\circ$ & $\circ$ & $\circ$ & $\circ$ & Strongly agree \\
\hline & \multicolumn{7}{|c|}{ I think it is easy to understand the picture when using VR. } \\
\hline & & 1 & 2 & 3 & 4 & 5 & \\
\hline & Strongly disagree & 0 & $\circ$ & $\circ$ & $\circ$ & $\circ$ & Strongly agree \\
\hline \multirow[t]{6}{*}{4.} & \multicolumn{7}{|c|}{$\begin{array}{l}\text { I think general construction navigation can help one to choose the navigation content according } \\
\text { to personal preferences. }\end{array}$} \\
\hline & & 1 & 2 & 3 & 4 & 5 & \\
\hline & Strongly disagree & 0 & $\circ$ & $\circ$ & $\circ$ & $\circ$ & Strongly agree \\
\hline & \multicolumn{7}{|c|}{ I think VR can adjust the navigation process to personal preferences. } \\
\hline & & 1 & 2 & 3 & 4 & 5 & \\
\hline & Strongly disagree & $\circ$ & $\circ$ & $\circ$ & $\circ$ & $\circ$ & Strongly agree \\
\hline
\end{tabular}

\section{Perceived Usefulness}

\begin{tabular}{|c|c|c|c|c|c|c|c|}
\hline \multirow[t]{6}{*}{1.} & \multicolumn{7}{|c|}{ I think the materials of general construction navigation are helpful for understanding the case. } \\
\hline & & 1 & 2 & 3 & 4 & 5 & \\
\hline & Strongly disagree & $\circ$ & o & $\circ$ & $\circ$ & o & Strongly agree \\
\hline & \multicolumn{7}{|c|}{ I think VR is helpful for understanding the case. } \\
\hline & & 1 & 2 & 3 & 4 & 5 & \\
\hline & Strongly disagree & 0 & 0 & 0 & 0 & 0 & Strongly agree \\
\hline \multirow[t]{6}{*}{2.} & \multicolumn{7}{|c|}{$\begin{array}{l}\text { I think the materials of general construction navigation enable me to know more about the } \\
\text { content of the case. }\end{array}$} \\
\hline & & 1 & 2 & 3 & 4 & 5 & \\
\hline & Strongly disagree & o & o & $\circ$ & 0 & 0 & Strongly agree \\
\hline & \multicolumn{7}{|c|}{ I think VR enables me to know more about the content of the case. } \\
\hline & & 1 & 2 & 3 & 4 & 5 & \\
\hline & Strongly disagree & o & o & o & o & o & Strongly agree \\
\hline \multirow[t]{6}{*}{3.} & \multicolumn{7}{|c|}{$\begin{array}{l}\text { I think the materials of general construction navigation enable me to know more about the } \\
\text { content of the case. }\end{array}$} \\
\hline & & 1 & 2 & 3 & 4 & 5 & \\
\hline & Strongly disagree & $\circ$ & $\circ$ & $\circ$ & $\circ$ & $\circ$ & Strongly agree \\
\hline & \multicolumn{7}{|c|}{ I think the use of VR can improve the efficiency of introducing the case. } \\
\hline & & 1 & 2 & 3 & 4 & 5 & \\
\hline & Strongly disagree & $\circ$ & o & $\circ$ & $\circ$ & ○ & Strongly agree \\
\hline 4. & \multicolumn{7}{|c|}{$\begin{array}{l}\text { I think the method of general construction navigation will enable users to feel immersed in the } \\
\text { real environment. }\end{array}$} \\
\hline & & 1 & 2 & 3 & 4 & 5 & \\
\hline & Strongly disagree & $\circ$ & o & $\circ$ & $\circ$ & o & Strongly agree \\
\hline & \multicolumn{7}{|c|}{ I think VR is more likely to enable users to feel immersed in the real environment. } \\
\hline & & 1 & 2 & 3 & 4 & 5 & \\
\hline
\end{tabular}




\begin{tabular}{|c|c|c|c|c|c|c|c|}
\hline & Strongly disagree & $\circ$ & ○ & $\circ$ & $\circ$ & $\circ$ & Strongly agree \\
\hline 5. & \multicolumn{7}{|c|}{$\begin{array}{l}\text { I think the environment of using general construction navigation contributes to the interaction } \\
\text { between users and the case. }\end{array}$} \\
\hline & & 1 & 2 & 3 & 4 & 5 & \\
\hline & Strongly disagree & $\circ$ & $\circ$ & $\circ$ & $\circ$ & $\circ$ & Strongly agree \\
\hline & \multicolumn{7}{|c|}{ I think the environment of using VR contributes to the interaction between users and the case. } \\
\hline & & 1 & 2 & 3 & 4 & 5 & \\
\hline & Strongly disagree & $\circ$ & $\circ$ & $\circ$ & $\circ$ & $\circ$ & Strongly agree \\
\hline 5. & \multicolumn{7}{|c|}{$\begin{array}{l}\text { I think it is more likely to gain the feelings a case would like to present through the materials of } \\
\text { general construction navigation. }\end{array}$} \\
\hline & & 1 & 2 & 3 & 4 & 5 & \\
\hline & Strongly disagree & $\circ$ & $\circ$ & $\circ$ & $\circ$ & $\circ$ & Strongly agree \\
\hline & \multicolumn{7}{|c|}{ I think it is easier to gain the feelings a case would like to present through VR. } \\
\hline & & 1 & 2 & 3 & 4 & 5 & \\
\hline & Strongly disagree & 0 & $\circ$ & $\circ$ & $\circ$ & $\circ$ & Strongly agree \\
\hline
\end{tabular}

\section{PART 4. Attitude Towards Using}

\begin{tabular}{|c|c|c|c|c|c|c|c|}
\hline \multirow[t]{6}{*}{1.} & \multicolumn{7}{|c|}{ I think it is a good thing to use the materials of general construction navigation. } \\
\hline & & 1 & 2 & 3 & 4 & 5 & \\
\hline & Strongly disagree & o & o & o & $\circ$ & $\circ$ & Strongly agree \\
\hline & \multicolumn{7}{|c|}{ I think it is a good thing to use VR. } \\
\hline & & 1 & 2 & 3 & 4 & 5 & \\
\hline & Strongly disagree & 0 & ○ & $\circ$ & $\circ$ & $\circ$ & Strongly agree \\
\hline \multirow[t]{6}{*}{2.} & \multicolumn{7}{|c|}{ I think the materials of the construction case are helpful to me. } \\
\hline & & 1 & 2 & 3 & 4 & 5 & \\
\hline & Strongly disagree & $\circ$ & $\circ$ & $\circ$ & $\circ$ & $\circ$ & Strongly agree \\
\hline & \multicolumn{7}{|c|}{ I think VR is helpful to me. } \\
\hline & & 1 & 2 & 3 & 4 & 5 & \\
\hline & Strongly disagree & $\circ$ & $\circ$ & $\circ$ & $\circ$ & $\circ$ & Strongly agree \\
\hline \multirow[t]{6}{*}{3.} & \multicolumn{7}{|l|}{ I like using VR. } \\
\hline & & 1 & 2 & 3 & 4 & 5 & \\
\hline & Strongly disagree & 0 & $\circ$ & $\circ$ & $\circ$ & $\circ$ & Strongly agree \\
\hline & \multicolumn{7}{|c|}{ I think it is a good thing to use VR. } \\
\hline & & 1 & 2 & 3 & 4 & 5 & \\
\hline & Strongly disagree & $\circ$ & $\circ$ & $\circ$ & $\circ$ & $\circ$ & Strongly agree \\
\hline \multirow[t]{6}{*}{4.} & \multicolumn{7}{|c|}{$\begin{array}{l}\text { I feel senses of curiosity and entertainment when using the materials of general construction } \\
\text { navigation. }\end{array}$} \\
\hline & & 1 & 2 & 3 & 4 & 5 & \\
\hline & Strongly disagree & o & $\circ$ & $\circ$ & $\circ$ & $\circ$ & Strongly agree \\
\hline & \multicolumn{7}{|c|}{ I feel senses of curiosity and entertainment when using VR. } \\
\hline & & 1 & 2 & 3 & 4 & 5 & \\
\hline & Strongly disagree & o & o & o & $\circ$ & $\circ$ & Strongly agree \\
\hline \multirow[t]{6}{*}{5.} & \multicolumn{7}{|c|}{$\begin{array}{l}\text { I think it is more likely to express spatial feeling when using the materials of general } \\
\text { construction navigation. }\end{array}$} \\
\hline & & 1 & 2 & 3 & 4 & 5 & \\
\hline & Strongly disagree & $\circ$ & $\circ$ & $\circ$ & $\circ$ & $\circ$ & Strongly agree \\
\hline & \multicolumn{7}{|c|}{ I think it is more likely to express spatial feelings when using VR. } \\
\hline & & 1 & 2 & 3 & 4 & 5 & \\
\hline & Strongly disagree & 0 & 0 & 0 & $\circ$ & $\circ$ & Strongly agree \\
\hline
\end{tabular}


PART 5. Intention to Use

\begin{tabular}{|c|c|c|c|c|c|c|c|}
\hline \multirow[t]{6}{*}{1.} & \multicolumn{7}{|c|}{$\begin{array}{l}\text { I think the materials of general construction navigation can enhance my intention to understand } \\
\text { the construction case. }\end{array}$} \\
\hline & & 1 & 2 & 3 & 4 & 5 & \\
\hline & Strongly disagree & $\circ$ & $\circ$ & $\circ$ & $\circ$ & ○ & Strongly agree \\
\hline & \multicolumn{7}{|c|}{ I think VR can enhance my intention to understand the construction case. } \\
\hline & & 1 & 2 & 3 & 4 & 5 & \\
\hline & Strongly disagree & $\circ$ & $\circ$ & ० & $\circ$ & $\circ$ & Strongly agree \\
\hline 2. & \multicolumn{7}{|c|}{$\begin{array}{l}\text { I have the intention to continue to use the materials of general construction navigation in the } \\
\text { future. }\end{array}$} \\
\hline & & 1 & 2 & 3 & 4 & 5 & \\
\hline & Strongly disagree & $\circ$ & $\circ$ & 0 & $\circ$ & $\circ$ & Strongly agree \\
\hline & \multicolumn{7}{|c|}{$\begin{array}{l}\text { I have the intention to continue to use VR to conduct general construction navigation in the } \\
\text { future. }\end{array}$} \\
\hline & & 1 & 2 & 3 & 4 & 5 & \\
\hline & Strongly disagree & $\circ$ & $\circ$ & $\circ$ & $\circ$ & $\circ$ & Strongly agree \\
\hline 3. & \multicolumn{7}{|c|}{ I hope other construction cases can also use the materials of general construction navigation. } \\
\hline & & 1 & 2 & 3 & 4 & 5 & \\
\hline & Strongly disagree & $\circ$ & $\circ$ & $\circ$ & $\circ$ & $\circ$ & Strongly agree \\
\hline & \multicolumn{7}{|c|}{ I hope other construction cases can also use VR. } \\
\hline & & 1 & 2 & 3 & 4 & 5 & \\
\hline & Strongly disagree & $\circ$ & $\circ$ & ० & $\circ$ & $\circ$ & Strongly agree \\
\hline 4. & \multicolumn{7}{|c|}{$\begin{array}{l}\text { On the whole, I think the materials of general construction navigation are a good way to } \\
\text { introduce a case. }\end{array}$} \\
\hline & & 1 & 2 & 3 & 4 & 5 & \\
\hline & Strongly disagree & $\circ$ & $\circ$ & $\circ$ & $\circ$ & $\circ$ & Strongly agree \\
\hline & \multicolumn{7}{|c|}{ On the whole, I think VR is a good way to introduce a case. } \\
\hline & & 1 & 2 & 3 & 4 & 5 & \\
\hline & Strongly disagree & $\circ$ & $\circ$ & $\circ$ & $\circ$ & $\circ$ & Strongly agree \\
\hline 5. & \multicolumn{7}{|c|}{ In the future, I will ask whether I can use VR to navigate when visiting construction cases. } \\
\hline & & 1 & 2 & 3 & 4 & 5 & \\
\hline & Strongly disagree & $\circ$ & $\circ$ & ० & $\circ$ & ○ & Strongly agree \\
\hline
\end{tabular}

\section{References}

1. Schneider, S.; Kuliga, S.; Hölscher, C.; Dalton, R.C.; Kunert, A.; Kulik, A.; Donath, D. Educating architecture students to design buildings from the inside out: Experiences from a research-based design studio. In Proceedings of the 9th International Space Syntax Symposium, Seoul, Korea, 31 October-3 November 2013; Kim, Y.O., Park, H.T., Seo, K.W., Eds.; Sejong University: Seoul, Korea, 2013.

2. Juan, Y.K.; Chien, S.F.; Li, Y.J. Customer Focused System for Pre-sale Housing Customisation Using Case-based Reasoning and Feng Shui Theory. Indoor Built Environ. 2010, 19, 453-464. [CrossRef]

3. Botden, S.M.; Torab, F.; Buzink, S.N.; Jakimowicz, J.J. The importance of haptic feedback in laparoscopic suturing training and the additive value of virtual reality simulation. Surg. Endosc. 2008, 22, 1214-1222. [CrossRef] [PubMed]

4. Kuliga, S.F.; Thrashb, T.; Daltonc, R.C.; Hölscher, C. Virtual reality as an empirical research tool—Exploring user experience in a real building and a corresponding virtual model. Comput. Environ. Urban Syst. 2015, 54, 363-375. [CrossRef]

5. Rubio-Tamayo, J.L.; Barrio, M.G.; García, F.G. Immersive Environments and Virtual Reality: Systematic Review and Advances in Communication, Interaction and Simulation. Multimodal Technol. Interact. 2017, 1, 21. [CrossRef]

6. Westerdahl, B.; Suneson, K.; Wernemyr, C.; Roupe, M.; Johansson, M.; Allwood, C.M. Users' evaluation of a virtual reality architectural model compared with the experience of the completed building. Autom. Constr. 2006, 15, 150-165. [CrossRef] 
7. Niu, S.; Pan, W.; Zhao, Y. A virtual reality integrated design approach to improving occupancy information integrity for closing the building energy performance gap. Sust. Cities Soc. 2016, 27, 275-286. [CrossRef]

8. Shushan, Y.; Portugali, J.; Blumenfeld-Lieberthal, E. Using virtual reality environments to unveil the imageability of the city in homogenous and heterogeneous environments. Comput. Environ. Urban Syst. 2016, 58, 29-38. [CrossRef]

9. Burdea, G. Virtual Reality Systems and Applications. In Proceedings of the Electro'93 International Conference, Short Course, Edison, NJ, USA, 28 April 1993; p. 164.

10. Cliburn, D.; Winlock, T. Dynamic landmark placement as a navigation aid in virtual worlds. In Proceedings of the 2007 ACM Symposium on Virtual Reality Software and Technology, Newport Beach, CA, USA, 5-7 November 2002; pp. 211-214.

11. Dalton, R.C. Spatial Navigation in Immersive Virtual Environments. Ph.D. Thesis, University College London, London, UK, 2001, unpublished.

12. Loomis, J.M.; Blascovich, J.J.; Beall, A.C. Immersive virtual environment technology as a basic research tool in psychology. Behav. Res. Methods Instrum. Comput. 1999, 31, 557-564. [CrossRef] [PubMed]

13. Larsen, C.R.; Oestergaard, J.; Ottesen, B.S.; Soerensen, J.L. The efficacy of virtual reality simulation training in laparoscopy: A systematic review of randomized trials. Acta Obstet. Gynecol. Scand. 2012, 91, 1015-1022. [CrossRef] [PubMed]

14. Heydarian, A.; Cameiro, J.P.; Gerber, D.; Becerik-Gerber, B. Immersive virtual environments, understanding the impact of design features and occupant choice upon lighting for building performance. Build. Environ. 2015, 89, 217-228. [CrossRef]

15. Osello, A.; Lucibello, G.; Morgagni, F. HBIM and virtual tools: A new chance to preserve architectural heritage. Buildings 2018, 8, 12. [CrossRef]

16. Drettakis, G.; Roussou, M.; Reche, A.; Tsingos, N. Design and evaluation of a realworld virtual environment for architecture and urban planning. Presence Teleoper. Virtual Environ. 2007, 16, 318-332. [CrossRef]

17. Broll, W.; Lindt, I.; Ohlenburg, J.; Wittkämper, M.; Yuan, C.; Novotny, T.; Strothman, A. Arthur: A collaborative augmented environment for architectural design and urban planning. J. Virtual Real. Broadcast. 2004, 1, 1-10.

18. Chang, C.O.; Ward, C.W. Forward pricing and the housing market: the pre-sales housing system in Taiwan. J. Prop. Res. 1993, 10, 217-227. [CrossRef]

19. Lai, R.N.; Wang, K.; Zhou, Y. Sale before completion of development: pricing and strategy. Real Estate Econ. 2004, 32, 329-357. [CrossRef]

20. Davis, E. TechGnosis: Myth, Magic, and Mysticism in the Age of Information; North Atlantic Books: Berkeley, CA, USA, 2015.

21. Cuieford, J.P. Fundamental Statistics in Psychology and Education, 4th ed.; McGraw Hill: New York, NY, USA, 1965.

22. Wells, J.; Wollack, J.A. An Instructor's Guide to Understanding Test Reliability. Available online: https: / / testing.wisc.edu/Reliability.pdf (accessed on 21 May 2018).

23. Vergara, D.; Rubio, M.P.; Lorenzo, M. On the design of virtual reality learning environments in engineering. Multimodal Technol. Interact. 2017, 1, 11. [CrossRef]

(c) 2018 by the authors. Licensee MDPI, Basel, Switzerland. This article is an open access article distributed under the terms and conditions of the Creative Commons Attribution (CC BY) license (http://creativecommons.org/licenses/by/4.0/). 